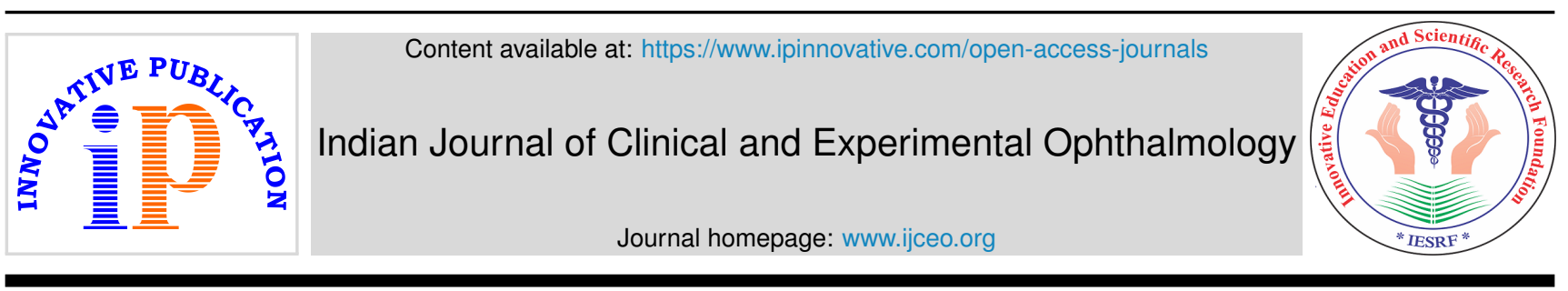

\title{
Editorial
}

\section{Tuberculosis of the Retina: A Review}

\author{
Rajendra P Maurya ${ }^{1}$,* \\ ${ }^{1}$ Regional Institute of Ophthalmology, Institute of Medical Sciences, Banaras Hindu University, Varanasi, Uttar Pradesh, India
}

\section{A R T I C L E I N F O}

Article history:

Received 06-03-2021

Accepted 18-03-2021

Available online 01-04-2021 (c) This is an open access article distributed under the terms of the Creative Commons Attribution License (https://creativecommons.org/licenses/by/4.0/) which permits unrestricted use, distribution, and reproduction in any medium, provided the original author and source are credited.
Tuberculosis (TB) remains the major cause of death and morbidity worldwide. Around two billion people are infected with Mycobacterium tuberculosis out of which around $10 \%$ develop the disease. ${ }^{1}$ The disease is categorized as pulmonary or extrapulmonary tuberculosis. Among the infected patients the incidence of extrapulmonary tuberculosis is around $15-20 \% .^{2}$ Whereas the incidence of ocular tuberculosis varies, ranging from $1-15 \%$ and can involve any structure of the human eye. ${ }^{3}$

Acid-fast Bacillus (AFB) disseminates hematogenously and can causes retinal disease. Tuberculosis of the retina most commonly results from choroidal extension. Choroidal tubercles mostly seen in terminally ill patients with tubercular meningitis or milliary tuberculosis. Tubercular chorioretinitis is often associated with retinal vasculitis and retinal vein occlusions. ${ }^{4}$ Choroidal tubercles mostly present as multiple white, gray lesions with or without hemorrhage and exudates,sometimes the presentation can be in the form of a tuberculoma of varying sizes (4-14 $\mathrm{mm})$. Other manifestations of choroidal tuberculosis are serpiginous choroiditis and multiple choroiditis.

Retinal lesions commonly present as a focal tubercules, diffuse retinitis or vitreous opacifications along with retinal vasculitis involving the veins. Retinal vasculitis is characterized by vitritis, neovascularization and retinal hemorrhage. ${ }^{5}$ Eale's disease is an idiopathic inflammatory retinal perivasculitis, mostly seen in young adult male and associated with recurrent vitreous hemorrhage. The hypersensitivity to tubercular protein has been proposed as a possible etiology of vascular inflammation Eale's disease. Mycobacterium DNA has been detected through polymerase chain reactions (PCR) in the vitreous and epiretinal membrane obtained from patients with Eale's disease.

The diagnosis of intraocular tuberculosis is quite difficult and challenging and is based on clinical findings, evidence of pulmonary manifestations and laboratory findings. In majority of the patients diagnosis requires tuberculin skin test (TST) and or interferon gamma release assay (IGRA). Detecting the genome of acid-fast bacillus by PCR is ideal for diagnosis. ${ }^{6}$ The PCR technique utilizing the MPB64 gene is highly sensitive and specific for diagnosis. ${ }^{7}$ Retinal imaging techniques like FFA, OCT, ICG and USG/Ultrasound biomicroscopy are also helpful in establishing the diagnosis. In tuberculous granuloma, OCT shows typical "contact sign", localized adhesion between the choriocapillaris-RPE layers and overlying neurosensory retina.

The treatment of chorioretinal tuberculosis / tubercular vasculitis includes anti-tuberculosis treatment (ATT), oral corticosteroids, laser photocoagulation and pars plana vitrectomy for persistent vitreous hemorrhage. ${ }^{8}$ Intravitreal anti-VEGF can be used for associated vein occlusion. ATT regimen for chorioretinal tuberculosis is like that for pulmonary $\mathrm{TB}$ and includes systemic multi-drug therapy for 6 to 9 months. The recommended protocol is an initial 2 month induction course of isoniazid, rifampin, pyrazinamide and ethambutol followed by 4-7 months of the 
combination of isoniazid and rifampin. ${ }^{9}$ Adjunctive lowdose corticosteroid therapy for 4-6 weeks is used to limit the inflammatory process which prevents the damage to the ocular tissue caused from delayed hypersensitivity. ${ }^{10}$

\section{References}

1. World Health Organization. Fact Sheet No; 2010.

2. Peto HM, Pratt RH, Harrington TA, Lobue PA, Armstrong LR. Epidemiology of extrapulmonary tuberculosis in the United States,1993-2006. Clin Infect Dis. 2009;49(9):1350-7.

3. Cutrufello NJ, Karakousis PC, Fishler J, Albini TA. Intraocular Tuberculosis. Ocul Immunol Inflamm. 2010;18(4):281-91.

4. Islam SM, Tabbara KF. Causes of uveitis at the eye center in Saudi Arabia: A retrospective review. Ophthalmic Epidemiol. 1997;9(4):239-49.

5. Gupta V, Gupta A, Rao NA. Intraocular Tuberculosis-An Update. Surv Ophthalmol. 2007;52(6):561-87.

6. Ang M, Wong W, Ngan CCL, Chee SP. Interferon-gamma release assay as a diagnostic test for tuberculosis-associated uveitis. Eye. 2012;26(5):658-65.

7. Babu K, Satish V, Satish S, SubbaKrishna DK, Abraham MP, Murthy $\mathrm{KR}$, et al. Utility of QuantiFERON TB gold test in a south Indian patient population of ocular inflammation. Indian J Ophthalmol. 2009;57(6):427-30.
8. Bansal R, Gupta A, Gupta V, Dogra MR, Bambery P, Arora SK, et al. Role of anti-tubercular therapy in uveitis with latent/manifest tuberculosis. Am J Ophthalmol. 2008;146(5):772-9.

9. Edlin BR, Tokars JI, Grieco MH, Crawford JT, Williams J, Sordillo EM, et al. An Outbreak of Multidrug-Resistant Tuberculosis among Hospitalized Patients with the Acquired Immunodeficiency Syndrome. N Engl J Med. 1992;326(23):1514-21.

10. Tabbara KF. Ocular Tuberculosis: Anterior Segment. Int Ophthalmol Clin. 2005;45(2):57-69.

\section{Author biography}

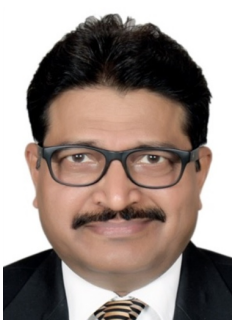

Rajendra P Maurya, (MS, Ph.D) Editor in Chief IJCEO, Associate Professor \& In-charge Orbit, Ocular Oncology and Oculoplasty Unit Regional Institute of Ophthalmology, Institute of Medical Sciences,

Banaras Hindu University, Varanasi, (UP), India E-mail: editorijceo@gmail.com,

mauryarp_bhu@yahoo.com

Cite this article: Maurya RP. Tuberculosis of the Retina: A Review. Indian J Clin Exp Ophthalmol 2021;7(1):175-176. 